\title{
Opioid use after propofol or sevoflurane anesthesia: a randomized trial
}

\section{Utilisation d'opioïdes après une anesthésie au propofol ou au sévoflurane: une étude randomisée}

\author{
Marita Windpassinger, MD - Olga Plattner, MD - Jana Gemeiner, MD · \\ Kornelia Böhler, MD • Robert Luntzer, MD - Walter Klimscha, MD • \\ Dongsheng Yang, MS · Edward J. Mascha, PhD · Daniel I. Sessler, MD
}

Received: 16 November 2015/Revised: 11 July 2016/ Accepted: 12 August 2016/Published online: 14 September 2016

(C) Canadian Anesthesiologists' Society 2016

\begin{abstract}
Background The intravenous anesthetic propofol is a gamma-aminobutyric acid A receptor agonist. Propofol promotes analgesia by depressing nociceptive transmission in peripheral neurons, antagonizing $N$-methyl-D-aspartate receptors, and activating gamma-aminobutyric acid A receptors in dorsal root ganglion receptor cells. Nevertheless, it remains unclear whether intraoperative propofol causes clinically meaningful postoperative analgesia. We therefore tested the hypothesis that patients anesthetized with sevoflurane require a greater quantity of postoperative opioids (from the end of surgery until the next postoperative morning) than those anesthetized with propofol.
\end{abstract}

M. Windpassinger, MD $\cdot$ O. Plattner, MD $\cdot$ J. Gemeiner, MD Department of Anaesthesiology and Intensive Care, Medical University of Vienna, Waehringer Guertel 18-20, 1090 Vienna, Austria

K. Böhler, MD

Department of Dermatology, Medical University of Vienna,

Waehringer Guertel 18-20, 1090 Vienna, Austria

R. Luntzer, MD · W. Klimscha, MD

Department of Anaesthesiology and Intensive Care, Danube

Hospital, Langobardenstrasse 122, 1220 Vienna, Austria

D. Yang, MS · E. J. Mascha, PhD

Department of Quantitative Health Sciences, Cleveland Clinic,

Cleveland, OH, USA

D. Yang, MS · E. J. Mascha, PhD · D. I. Sessler, MD ( $\varangle)$ Department of Outcomes Research, Anesthesiology Institute, Cleveland Clinic, 9500 Euclid Ave - P77, Cleveland, OH 44195, USA

e-mail: DS@OR.org

URL: http://www.OR.org
Methods With Institutional Review Board and EudraCT Number approval (2009-011038-82) and patients' informed consent, ninety patients scheduled for open vein stripping were randomized to either sevoflurane or propofol anesthesia at the Medical University of Vienna General Hospital and the Danube Hospital, the largest regional hospital in Vienna. Pain was treated with bolus piritramide and patient-controlled morphine hydrochloride. The primary outcome was total opioid use from the end of surgery until the first postoperative morning. For the initial four postoperative hours and on the first postoperative morning, a blinded investigator recorded pain scores on an 11-point Likert verbal response scale.

Results The median [interquartile range] morphine sulfate equivalents were 9.8 [4-19] $\mathrm{mg}$ in the sevoflurane group and 10 [6-20] $\mathrm{mg}$ in the propofol group. Sevoflurane was not superior to propofol on postoperative opioid consumption, giving a ratio of means of 0.91 (95\% interimadjusted confidence interval [CI], 0.33 to $2.45 ; P=0.74$ ). Additionally, no difference in pain scores was found over time between the two groups, with a mean difference on an 11-point scale of 0.20 (95\% interim-adjusted CI, -0.36 to $0.73 ; P=0.31$ ).

Conclusion Intraoperative sevoflurane did not reduce postoperative analgesia. This finding is consistent with the results in most previous reports. This trial was registered at ClinicalTrials.gov: NCT00712517.

\section{Résumé}

Contexte Le propofol, un anesthésique administré par voie intraveineuse, est un agoniste des récepteurs de l'acide gamma-aminobutyrique A (GABA-A). Le propofol favorise l'analgésie en réduisant la transmission de la 
nociception dans les neurones périphériques, en antagonisant les récepteurs du N-méthyl-D-aspartate, et en activant les récepteurs GABA-A dans les cellules réceptrices du ganglion de la racine dorsale. Toutefois, nous ne savons pas si le propofol administré en période peropératoire provoque une analgésie postopératoire significative d'un point de vue clinique. C'est pourquoi nous avons testé l'hypothèse selon laquelle les patients anesthésiés avec du sévoflurane nécessiteraient une quantité plus importante d'opiö̈des en période postopératoire (de la fin de la chirurgie jusqu'au premier matin postopératoire) que les patients anesthésiés avec du propofol.

Méthode Ayant reçu l'approbation d'un Comité d'éthique et un numéro EudraCT (2009-011038-82) et obtenu le consentement éclairé des patients, quatre-vingt-dix patients devant subir une chirurgie ouverte des varices (open vein stripping) ont été randomisés à recevoir une anesthésie à base de sévoflurane ou de propofol à l'Université médicale de l'Hôpital général de Vienne ou au Donauspital, le plus grand hôpital régional de Vienne. La douleur a été traitée à l'aide d'un bolus de piritramide et de chlorhydrate de morphine en analgésie contrôlée par le patient. Le critère d'évaluation principal était la consommation totale d'opiö̈des entre la fin de la chirurgie et lendemain matin. Durant les quatre premières heures postopératoires et le matin suivant l'opération, un chercheur en aveugle a enregistré les scores de douleur sur une échelle de réponse verbale de Likert à 11 points à.

Résultats La médiane [écart interquartile] d'équivalent de sulfate de morphine était 9,8 [4-19] mg dans le groupe sévoflurane et de 10 [6-20] mg dans le groupe propofol. Le sévoflurane ne s'est pas avéré supérieur au propofol en ce qui touchait à la consommation d'opioüdes en période postopératoire, avec un rapport de moyennes de 0,91 (intervalle de confiance [IC] provisoire ajusté $95 \%, 0,33$ à 2,4; $P=0,74)$. En outre, aucune différence n'a été observée dans les scores de douleur au fil du temps entre les deux groupes, la différence moyenne sur l'échelle à 11 points atteignant 0,20 (IC provisoire ajusté $95 \%,-0,36$ à $0,73 ; P=0,31)$.

Conclusion Le sévoflurane peropératoire n'a pas réduit les besoins en analgésie postopératoire. Cette observation concorde avec les résultats de la plupart des comptes rendus déjà publiés. Cette étude a été enregistrée au ClinicalTrials.gov : NCT00712517.

Postoperative pain might be ameliorated by substituting propofol for sevoflurane anesthesia. Support for this theory comes from human pain models in which propofol reduced hyperalgesia and allodynia in response to pinprick and electric stimulation. ${ }^{1}$ Benefit may result from central and peripheral analgesic effects of sub-hypnotic doses of propofol, including suppression of spinal sensitization.

For example, animal experiments show that propofol depresses nociceptive transmission in neurons, thus diminishing the continued nociceptive barrage that normally follows tissue injury. ${ }^{2,3}$ Additional analgesic effects of propofol likely result from interactions with N-methyl-D-aspartate (NMDA), non-NMDA receptors, and via activation of gamma-aminobutyric acid $\mathrm{A}\left(\mathrm{GABA}_{\mathrm{A}}\right)$ receptors in the dorsal root ganglion nociceptor cells.

Consistent with multiple analgesic mechanisms, some studies report that patients anesthetized with propofol have less postoperative pain than those anesthetized with volatile anesthestics. ${ }^{4,5}$ Other studies, however, do not support a postoperative analgesic effect of intraoperative propofol. ${ }^{6-8}$ In fact, Boccara et al. showed that isoflurane in $\mathrm{N}_{2} \mathrm{O} / \mathrm{O}_{2}$ with 1-1.5 MAC provided better analgesia than propofol in patients recovering from abdominoplasty. ${ }^{6}$

Since it remains unclear whether intraoperative propofol analgesia ameliorates postoperative pain, we tested the primary hypothesis that postoperative opioid requirements (from the end of surgery until the next postoperative day) are greater in patients anesthetized with sevoflurane than in those anesthetized with propofol. Our secondary outcome was the average pain score for each group during the first four postoperative hours.

\section{Methods}

With Institutional Review Board and EudraCT Number approval (2009-011038-82) and patients' written informed consent, we enrolled participating inpatients scheduled for open vein stripping under general anesthesia at the two biggest hospitals in Vienna, the Medical University of Vienna General Hospital and the Donauspital. Each patient had insufficiency of the vena saphena magna and/or the vena saphena parva valve. A single surgeon in each hospital performed each study case. All participating patients were aged 18-75 yr and American Society of Anesthesiologists physical status I-III.

We excluded patients who routinely took any analgesics. Similarly, we excluded patients with a history of allergies to morphine or morphine derivatives, patients incapable of using an intravenous patient-controlled analgesia pump, and patients who could not reliably report pain intensity.

Protocol

Participating patients were given oral midazolam $7.5 \mathrm{mg}$ preoperatively on the morning of surgery. They were then randomized 1:1 and stratified by site to either propofol- 
based total intravenous anesthesia or sevoflurane-based volatile anesthesia. Randomization was based on computer-generated codes that were maintained in sequentially numbered opaque envelopes and opened shortly before induction of anesthesia.

Anesthesia started with a remifentanil infusion at a rate of $0.15-0.4 \mu \mathrm{g} \cdot \mathrm{kg}^{-1} \cdot \mathrm{min}^{-1}$. Thereafter, the designated anesthetic was initiated per randomized allocation: 1) propofol at $3-5 \mathrm{mg} \cdot \mathrm{kg}^{-1}$ or 2) sevoflurane at $5-6 \%$. Each patient's airway was secured with a supraglottic airway device or, after administration of rocuronium $0.5 \mathrm{mg} \cdot \mathrm{kg}^{-1}$, an endotracheal tube. Their lungs were mechanically ventilated with oxygen in air to maintain an end-tidal partial pressure of $\mathrm{CO}_{2}$ from $35-40 \mathrm{mmHg}$.

In patients assigned to propofol, anesthesia was maintained with an infusion of $2.5-3.0 \mathrm{mg} \cdot \mathrm{kg}^{-1} \cdot \mathrm{hr}^{-1}$. For those assigned to sevoflurane, anesthesia was maintained at an end-tidal concentration of 1.5-2.5\%. Anesthetics were adjusted as necessary to target a bispectral index (BIS) near 50 or a Narcotrend value near 40 (see below for details). The remifentanil infusion, which continued throughout surgery, was adjusted to target a mean arterial pressure within $20 \%$ of each participant's preoperative baseline pressure.

About ten minutes before the end of surgery, administration of anesthetic drugs and remifentanil was reduced and then discontinued when appropriate. The supraglottic airway device or endotracheal tube was removed, and patients were taken to the postanesthesia care unit where they remained for a minimum of four hours.

A patient-controlled analgesia pump containing morphine hydrochloride in a concentration of $2.5 \mathrm{mg} \cdot \mathrm{mL}^{-1}$ was connected and set to deliver 2-mg boluses with a seven-minute lockout window and no basal rate. Patient-controlled analgesia was maintained until the first postoperative morning, typically about 8 AM.

Pain scores exceeding three points prompted administration of $1.5 \mathrm{mg}$ of the opioid piritramide, which was repeated as necessary.

\section{Measurements}

Use of an 11-point Likert verbal response scale was explained to patients preoperatively. Hypnotic depth was estimated from a Narcotrend Compact M Monitor (MT MonitorTechnik GmbH, Bramsted, Germany) or a BIS Monitoring System (BISx, Covidien, Dublin, Ireland). Routine anesthetic monitor values as well as propofol and remifentanil infusion rates were recorded at five-minute intervals.

Surgeons were blinded to randomization and anesthetic management. Independent clinicians and investigators, also blinded to randomization and anesthetic management, performed all postoperative measurements. To maintain blinding, an unblinded anesthesiologist retained the electronic printout of the anesthesia record, and the blinded study personnel were instructed not to access the electronic medical record. A study nurse blinded to group assignment controlled all postoperative pain scores and opioid administration.

Verbal response pain scores as well as opioid consumption and adverse effects were assessed at rest at 30-min intervals for the initial four postoperative hours. The next morning, patients were asked to rate their average pain since leaving the postanesthesia care unit. The amount of opioid consumed during this period was recorded. Piritramide (a morphine-like opioid) was converted to morphine equivalents using the formula: $10 \mathrm{mg}$ morphine $=$ $15 \mathrm{mg}$ piritramide. Adverse effects, including nausea and antiemetic treatments, were recorded.

\section{Endpoints}

The primary efficacy endpoint was postoperative opioid consumption from the end of surgery until the first postoperative morning. The pre-specified secondary outcome was postoperative pain measured during the first four hours of recovery after surgery. An exploratory outcome was pain on the first postoperative morning.

Other exploratory outcomes included intraoperative remifentanil consumption, total amount of fluids, BIS, intraoperative and postoperative blood pressure, heart rate, $\mathrm{SaO}_{2}$, and postoperative side effects (vomiting and nausea). Variables captured at repeated intervals (i.e., blood pressure, heart rate, $\mathrm{SaO}_{2}$, and BIS) were averaged within each patient. The occurrence of nausea and vomiting was evaluated at 30-min intervals throughout the first four hours of recovery, and the next morning, patients were asked if they had experienced nausea or vomiting since leaving the recovery unit. Any positive response for nausea or vomiting at any time was considered evidence of postoperative nausea and vomiting.

Statistical analysis

Balance on baseline characteristics and intraoperative factors was assessed between the randomized groups using the standardized difference, i.e., the difference in means or proportions divided by the pooled standard deviation. Imbalance was defined as a standardized difference greater than the absolute value of $1.96 \sqrt{\frac{n_{1}+n_{2}}{n_{1} \times n_{2}}}=0.41 .^{9}$ Where $n_{1}=42$ and $n_{2}=48$.

We assessed the effect of sevoflurane vs propofol on the primary outcome of opioid consumption using a two-tailed Student's $t$ test on the log-transformed data along with a 
two-sided interim-adjusted $95 \%$ confidence interval (CI). We added 0.1-mg iv morphine equivalents to six patients who received zero opioids before taking the logarithm. Results were back-transformed (i.e., exponentiated) to obtain the estimated ratio of geometric means and $95 \% \mathrm{CI}$ on the raw scale.

For postoperative pain scores repeated over time, a linear mixed-effects model was used to estimate the difference in means between sevoflurane and propofol, assuming an unstructured within-subject correlation matrix. If our findings showed an interaction between intervention and time $(P<0.10)$, superiority would be assessed separately at each time point.

Superiority testing was also used for tertiary outcomes. Randomized groups were compared on continuous secondary outcomes with the Student's $t$ test or Wilcoxon rank-sum test and on binary secondary outcomes with the Chi square or Fisher's exact test, as appropriate.

We planned to assess efficacy and futility at each $25 \%$ of the maximum sample size using two-sided superiority tests. We used a group sequential design with a gamma spending function (gamma parameter of -1 for efficacy [alpha] and -4 for futility [beta]). The $P$ values constituting the efficacy (futility) boundaries at each of the four planned analyses were $P \leq 0.0016(>0.90), P \leq$ 0.0048 ( $>0.61), P \leq 0.0147$ ( $>0.20)$, and $P \leq 0.0440$

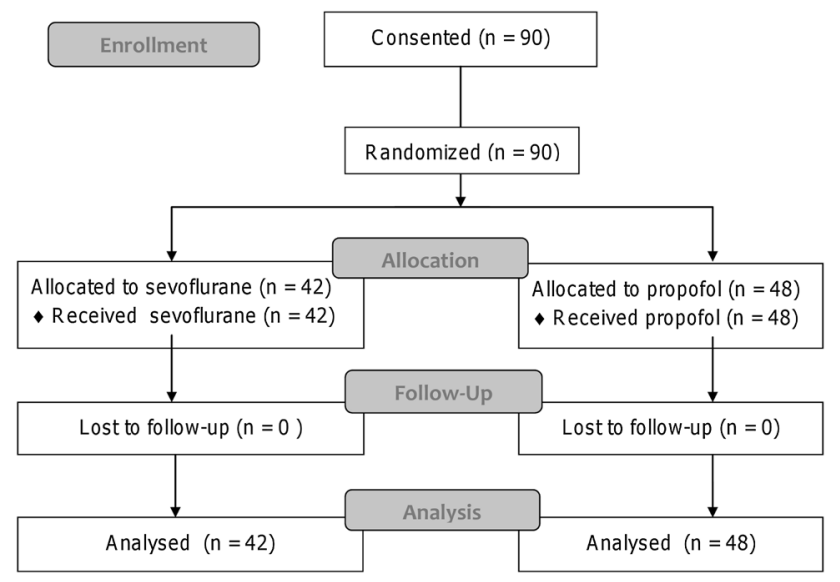

Fig. 1 Enrolment, randomization, and analysis
(>0.0440), respectively. Results are expressed as mean (SD) or difference in means.

The significance level of two-sided superiority testing was 0.05 for each of the primary and secondary outcomes. Tertiary outcomes were assessed at an overall significance level of 0.05 , with Bonferroni correction for multiple testing.

In fact, we conducted only two interim analyses so that results at the final analysis $(n=90)$ were reported using the Z-statistic efficacy criterion of 3.191, corresponding to an interim-adjusted significance criterion of $P<0.0014$ for the two-sided tests (overall alpha of 0.05). All statistical analyses were performed using $\mathrm{SAS}^{\circledR}$ statistical software, version 9.3 (SAS institute, Carey, NC, USA).

\section{Sample size}

A previous study of hysterectomy patients reported 24-hr mean (SD) morphine consumption of 32 (15) mg with propofol and 49 (18) $\mathrm{mg}$ with sevoflurane, with $n=40$ patients per group. ${ }^{2}$ Vein stripping is presumably less painful than a hysterectomy. We thus estimated that our patients would require about half the opioid dose, but the treatment effect expressed as a percentage would be comparable.

We planned for 136 patients (68 per group). A planned interim analysis indicated more variation than expected and resulted in our expansion to 310 patients (155 patients per group). The revised study with 155 participants per group had $80 \%$ power at the 0.05 significance level (two-tailed) to detect superiority of sevoflurane to propofol on mean opioid consumption using a ratio of means of 1.33 and assuming a coefficient of variation of 1.0, including adjustments for interim monitoring. The study was in fact stopped at 90 patients (42 sevoflurane, 48 propofol) for logistical reasons.

\section{Results}

We report the results of 90 (42 sevoflurane, 48 propofol) of the 310 required participants who completed the study.

Table 1 Baseline characteristics of the patients $(n=90)$

\begin{tabular}{|c|c|c|c|}
\hline Factor & $\begin{array}{l}\text { Sevoflurane } \\
(n=42)\end{array}$ & $\begin{array}{l}\text { Propofol } \\
(n=48)\end{array}$ & ASD* \\
\hline Female, $n(\%)$ & $26(62)$ & $26(54)$ & 0.16 \\
\hline Age, mean (SD) & $51(13)^{\mathrm{a}}$ & $52(14)^{\mathrm{a}}$ & 0.10 \\
\hline Body mass index, mean (SD) & $28(4)$ & $27(4)$ & 0.22 \\
\hline
\end{tabular}


Ninety patients were randomized to sevoflurane ( $n=42$ ) or propofol $(n=48)$ during the study period which lasted from September 2010 through May 2014 (Fig. 1). Thereafter, open vein stripping at both participating hospitals was virtually completely replaced by an endovascular laser treatment which causes much less pain. The Executive Committee (D.I.S. and E.J.M.) stopped the study because patients meeting the original enrolment criteria were no longer readily available. The decision was made based on patient availability without access to study results.

Baseline characteristics were well balanced between groups, i.e., all absolute standardized differences $<0.41$ (Table 1).

The observed median [interquartile range (IQR)] morphine sulfate equivalents were 9.8 [4-19] $\mathrm{mg}$ in the sevoflurane group and 10 [6-20] $\mathrm{mg}$ in the propofol group. Superiority of sevoflurane to propofol on postoperative opioid consumption was not found, with an observed ratio of geometric means of 0.91 (95\% interim-adjusted CI, 0.33 to $2.45 ; P=0.74$ ) (Table 2, Fig. 2).

No difference was found between sevoflurane and propofol on postoperative pain scores in the postanesthesia care unit, first postoperative morning, or overall, with a mean difference on an 11-point Likert verbal response scale of 0.20 points $(95 \%$ interim-adjusted CI, -0.36 to $0.73 ; P=0.31$ ) collapsing over time (Table 2 , Fig. 3). No interaction was found between the intervention effect and measurement time $(P=0.56)$. The mean (SD) pain score was $1.6(1.3)$ in the sevoflurane group and 1.4 (1.2) in the propofol group. A sensitivity analysis using Wilcoxon rank-sum tests showed similar results and the same conclusions.

Furthermore, no differences were found between sevoflurane and propofol on secondary outcomes using two-tailed tests for superiority and adjusting for multiple testing and interim monitoring (all $P$ values $>0.00011$ ) (Table 3).

\section{Discussion}

We found that opioid use and pain scores were no worse with sevoflurane than with propofol anesthesia. In fact, similar median pain scores were observed throughout the initial four postoperative hours and on the first postoperative morning. Furthermore, we found no differences in opioid consumption, although the plausible range for the ratio of mean consumption for sevoflurane to

\section{Cumulative Morphine (mg)}

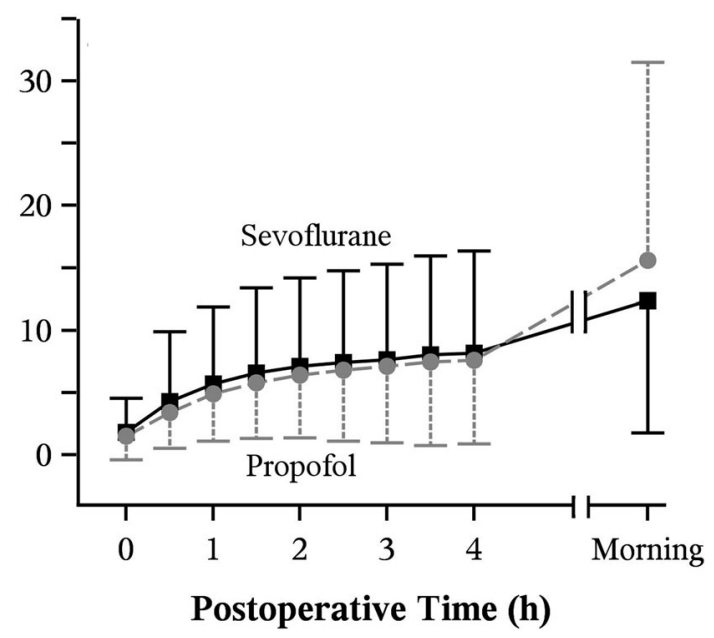

Fig. 2 Cumulative morphine equivalents over time by two interventions. Results are shown as mean (SD). PostOP = postoperative

Table 2 Comparing sevoflurane and propofol on primary and secondary outcomes

\begin{tabular}{llll}
\hline Outcome & $\begin{array}{l}\text { Sevoflurane } \\
(n=42)\end{array}$ & $\begin{array}{l}\text { Propofol } \\
(n=48)\end{array}$ & $\begin{array}{l}\text { Ratio of means } \\
(95 \% \text { CI })^{*}\end{array}$ \\
\hline Postoperative morphine equivalents (mg) & $9.8(4,19)$ & $10(6,20)$ & $0.91(0.33,2.45)$ \\
\hline Pain (0-10 Likert scale) & & $\begin{array}{l}\text { Difference in means } \\
(95 \% \text { CI)* }\end{array}$ \\
\hline Treatment*time interaction & & $1.4(1.2)$ & $0.20(-0.36,0.73)$ \\
Overall & $1.6(1.3)$ & $1.8(0.9)$ & 0.56 \\
PACU & $2.0(1.0)$ & $0.9(1.3)$ & 0.31 \\
First postoperative morning & $1.2(1.4)$ & & \\
\hline
\end{tabular}

Data are presented as mean (SD) or median (IQR: first-third quartiles)

* Interim-adjusted $95 \%$ confidence intervals using Z-statistic criterion of 3.191, with corresponding pre-specified $P$ value boundaries for superiority (efficacy) at this analysis of $P>0.0014$

** $P$ values from the two-sided $t$ test for postoperative morphine equivalents, and the linear mixed effects model for postoperative pain score. Superiority was not found for postoperative morphine equivalents and overall pain score 
propofol was 0.33 to 2.45 . The observed median [IQR] morphine sulfate equivalents were 9.8 [4-19] $\mathrm{mg}$ for sevoflurane and 10 [6-20] mg for propofol.

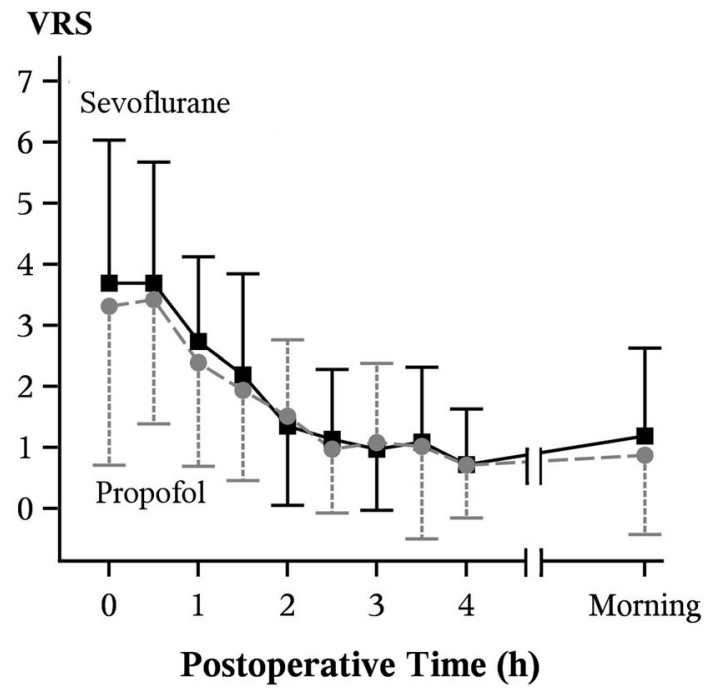

Fig. 3 Plot of verbal response scores (VRS) on a scale from 0-10 for pain over time by two interventions. Morning $=$ first postoperative morning. Verbal response scores were recorded at 30-min intervals in the postanesthesia care unit and during the first postoperative morning. Results are shown as mean (SD)
Our results diverge from some reports ${ }^{4,5}$ but are consistent with many clinical trials ${ }^{6-8}$ and animal studies showing that sub-hypnotic concentrations of propofol alone are not analgesic. ${ }^{2,3,10}$ They are also consistent with human pain models showing that, after propofol is discontinued, pain scores, hyperalgesia, and allodynia return to normal. Similarly, studies in volunteers indicate that opioids must be added to propofol to provide satisfactory pain relief. ${ }^{11,12}$ Conflicting reports may result, at least in part, from differing methodology, including induction strategy, use of opioids with various durations of action, analgesic regimes (non-opioids, nitrous oxide), various postoperative evaluation periods, and differing amounts of tissue trauma. ${ }^{4-6,8,11,13}$

Our results are generally consistent with a 2012 metaanalysis. ${ }^{13}$ Among the 25 randomized-controlled trials, ten studies with a total of 773 patients were considered suitable for comparing pain after propofol or volatile anesthesia. Four studies did not show significant differences in postoperative pain or analgesia requirements, ${ }^{14-17}$ and one study even showed significantly less pain 30 min postoperatively in children anesthetized with isoflurane $v s$ propofol or short-acting analgesics. ${ }^{18}$ Five other studies suggested benefit from

Table 3 Comparison of randomized groups on intraoperative and postoperative exploratory outcomes

\begin{tabular}{|c|c|c|c|c|}
\hline Outcome & $\begin{array}{l}\text { Sevoflurane } \\
(n=42)\end{array}$ & $\begin{array}{l}\text { Propofol } \\
(n=48)\end{array}$ & $\begin{array}{l}\text { Difference in means } \\
\text { (sevoflurane - propofol) } \\
95 \% \mathrm{CI}^{*}\end{array}$ & $P$ value** \\
\hline \multicolumn{5}{|l|}{ Intra-operative } \\
\hline Remifentanil (mg) & $1.5(0.6)$ & $1.4(0.7)$ & $0.1(-0.5,0.67)$ & 0.43 \\
\hline Fluid (ml) & $1340(464)$ & $1127(407)$ & $213(-158,585)$ & 0.02 \\
\hline Heart rate (bpm) & $59(13)$ & $55(8)$ & $4.0(-5.1,13.1)$ & 0.08 \\
\hline SBP (mmHg) & $95(10)$ & $100(13)$ & $-5.5(-15.9,4.9)$ & 0.04 \\
\hline DBP (mmHg) & $58(11)$ & $61(9)$ & $-2.6(-10.9,5.8)$ & 0.22 \\
\hline $\mathrm{SaO}_{2}(\%)$ & $99(1)$ & $99(1)$ & $-0.3(-1.0,0.5)$ & 0.16 \\
\hline BIS & $45(7)$ & $46(8)$ & $-0.9(-7.5,5.7)$ & 0.58 \\
\hline \multicolumn{5}{|l|}{ Postoperative } \\
\hline Heart rate (bpm) & $72(11)$ & $68(9)$ & $4.1(-4.1,12.4)$ & 0.05 \\
\hline SBP $(\mathrm{mmHg})$ & $130(17)$ & $127(16)$ & $3.0(-11.0,17.1)$ & 0.39 \\
\hline DBP $(\mathrm{mmHg})$ & $78(10)$ & $76(9)$ & $1.4(-6.9,9.6)$ & 0.51 \\
\hline \multirow[t]{2}{*}{$\mathrm{SaO}_{2}$} & $98(2)$ & $98(2)$ & $0.3(-1.2,1.7)$ & 0.43 \\
\hline & & & Relative Risk 95\% CI* & \\
\hline Vomiting-no. $\%$ & $8(19)$ & $8(17)$ & $1.1(0.2,6.2)$ & 0.77 \\
\hline PACU & $4(10)$ & $6(13)$ & & \\
\hline Postoperative day 1 & $7(17)$ & $8(17)$ & & \\
\hline Nausea-no. \% & $9(21)$ & $9(19)$ & $1.1(0.2,5.8)$ & 0.75 \\
\hline
\end{tabular}

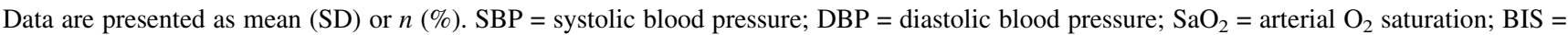
bispectral index; PACU $=$ post-anesthesia care unit

* Confidence intervals are interim-adjusted and Bonferroni-adjusted criteria to maintain overall 0.05 significance level

** $P$ values from two-side $t$ test or Chi square test, as appropriate. No comparisons are statistically significant using the interim and Bonferroniadjusted criteria of $P<0.0014 / 13=0.00011$ 
propofol. ${ }^{13,19-22}$ The overall reported effect was a $40 \%$ non-significant reduction in pain amongst patients treated with propofol compared with a volatile anesthetic. Nevertheless, the results are not directly comparable because many of the protocols differed substantially from ours. Substantive differences included use of nitrous oxide, ${ }^{14,15,18,20}$ volatile anesthetics other than sevoflurane,${ }^{14,15,19,20}$ opioids of differing durations, ${ }^{21}$ various postoperative analgesic strategies, multimodal pain regimes, ${ }^{21}$ and various primary outcomes. ${ }^{14-17,20}$

Our methods extend previous results. For example, propofol was not administered to our sevoflurane patients, even for induction, whereas in previous studies, anesthesia was often induced with propofol in both study groups. ${ }^{4,6,8,21}$ Furthermore, for maintenance of analgesia, we used remifentanil rather than fentanyl or morphine as they accumulate and thus remain active postoperatively. ${ }^{4,6,16}$ Importantly, we avoided nitrous oxide, an NMDA antagonist, ${ }^{23}$ thus potentially providing analgesia at the level of the spinal cord. Ohashi et al. showed that brain stem opioidergic and GABAergic neurons mediate the antinociceptive effect of nitrous oxide in Fischer rats. ${ }^{24}$ The effect was inhibited by the opioid receptor antagonist naloxone and the GABAergic receptor antagonist muscimol. Consistent with this mechanism, Fassoulaki et al. ${ }^{25}$ used nitrous oxide in each of their anesthetic groups (propofol, sevoflurane, and desflurane) and showed no differences in pain scores and opioid consumption among the groups.

Pain scores in our patients were only moderate, with average initial averages being 3-4 points on an 11-point Likert scale. As might be expected, opioid use was modest, averaging only 13-14 mg over the initial $24 \mathrm{hr}$ - which was much less than in other studies. ${ }^{4,26}$ It remains possible that the putative analgesic effects of propofol would be more apparent in patients experiencing more postoperative pain. More likely, however, the moderate pain levels in our patients provided the best chance of identifying subtle propofol-induced analgesia.

Perhaps the most serious weakness of our study is recruitment of only 90 of the 310 participants required to show the pre-specified clinically important difference in opioid consumption. This is clearly reflected in our confidence interval for the ratio of means in opioid consumption, which ranges from a $67 \%$ reduction to a 2.4- fold increase. Our findings cannot be considered definitive but do add to our knowledge. Using previously published data ${ }^{4}$ we initially estimated that 68 patients per group would be sufficient. The first interim analysis showed that population variability was twice what we expected and that more patients would be needed, up to a maximum of 155 patients per group. Nevertheless, we were forced to stop the study with a total enrolment of just 90 patients because of a radical shift in surgical technique. This shift from the conventional open approach to an endovascular laser technique causes much less pain and thus was not comparable with our initial surgical technique. A strength of our study is that only two surgeons participated and each used a similar operative technique. Consequently, tissue trauma and consequent pain was presumably comparable.

In summary, although our trial was stopped early, we did not find evidence consistent with the hypothesis that opioid consumption or pain scores were greater with sevoflurane than with propofol anesthesia. Our results add to a body of evidence in both clinical and animal models that question a propofol-related analgesic effect. Thus, while clinicians might have reasons for favouring propofol anesthesia, postoperative analgesia should not be among them.

\section{Conflicts of interest None declared.}

Author contributions Daniel I. Sessler contributed substantially to all aspects of this manuscript, including conception and design; acquisition, analysis, and interpretation of data, and drafting the article. Olga Plattner and Marita Windpassinger contributed substantially to the conception and design of the manuscript. Olga Plattner, Marita Windpassinger, Walter Klimscha, Robert Luntzer, Jana Gemeiner, and Kornelia Böhler contributed substantially to the acquisition of data. Dongsheng Yang and Edward J. Mascha contributed to study design and analysis of data. Olga Plattner, Marita Windpassinger, and Walter Klimscha contributed substantially to the interpretation of data.

Editorial responsibility This submission was handled by Dr. Gregory L. Bryson, Deputy Editor-in-Chief, Canadian Journal of Anesthesia.

\section{References}

1. Bandschapp $O$, Filitz J, Ihmsen $H$, et al. Analgesic and antihyperalgesic properties of propofol in a human pain model. Anesthesiology 2010; 113: 421-8.

2. Jewett BA, Gibbs LM, Tarasuik A, Kendig J. Propofol and barbiturate depression of spinal nociceptive neurotransmission. Anesthesiology 1992; 77: 1148-54.

3. Sun $Y Y$, Li KC, Chen J. Evidence for peripherally antinociceptive action of propofol in rats: behavioral and spinal neuronal responses to subcutaneous bee venom. Brain Res 2005; 1043: 231-5.

4. Cheng S, Yeh J, Flood P. Anaesthesia matters: patients anaesthetized with propofol have less postoperative pain than those anesthetized with isoflurane. Anesth Analg 2008; 106: 2649.

5. Tan T, Bhinder R, Carey $M$, Briggs $L$. Day-surgery patients anesthetized with propofol have less postoperative pain than those anaesthetized with sevoflurane. Anesth Analg 2010; 111: 83-5.

6. Boccara G, Mann C, Pouzeratte Y, Bellavoir A, Rouvier A, Colson $P$. Improved postoperative analgesia with isoflurane than with propofol anaesthesia. Can J Anaesth 1998; 45: 938-42. 
7. Hatem A Tawfik, Mohsen M. Sevoflurane versus propofol sedation during periocular anesthetic injections in oculoplastic procedures: An open-label randomized comparison. Saudi J Ophtalmol 2015; 29: 126-9.

8. Oritz J, Chang LC, Tolpin DA, Minard CG, Scott BG, Rivers JM. Randomized, controlled trial comparing the effects of anesthesia with propofol, isoflurane, desflurane and sevoflurane on pain after laparoscopic cholecystectomy. Braz J Anesthesiol 2014; 64: 14551.

9. Austin PC. Balance diagnostics for comparing the distribution of baseline covariates between treatment groups in propensity-score matched samples. Stat Med 2009; 28: 3083-107.

10. Abraham SE, Yaksh TL. Morphine, but not inhalation anesthesia, blocks post-injury facilitation. The role of preemptive suppression of afferent transmission. Anesthesiology 1993; 78: 713-21.

11. Zacny JP, Coalson DW, Young CJ, et al. Propofol at conscious sedation doses produces mild analgesia to cold pressor-induced pain in healthy volunteers. J Clin Anesth 1996; 8: 469-74.

12. Anker-Moller E, Spanberg N, Arendt-Nielsen L, Schultz P, Kristensen MS, Bjerring P. Subhypnotic doses of thiopentone and propofol cause analgesia to experimentally induced acute pain. Br J Anaesth 1991; 66: 185-8.

13. Hasani A, Jashari H, Gashi V, Dervishi A. Propofol and postoperative pain: systematic review and meta-analysis. In: Racz GB, Noe CE (Eds). Pain Management - Current Issues and Opinions. InTech 2012; 11: 223-42.

14. Eriksson H, Korttila $K$. Recovery profile after desflurane with or without ondansetron compared with propofol in patients undergoing outpatient gynecological laparoscopy. Anesth Analg 1996; 82: 533-8.

15. Doze VA, Schafer A, White PF. Propofol-nitrous oxide versus thiopental-isoflurane-nitrous oxide for general anesthesia. Anesthesiology 1988; 69: 63-71.

16. Jellish WS, Leonetti JP, Murdoch JR, Fowles S. Propofol-based anesthesia as compared with standard anesthetic techniques for middle ear surgery. J Clin Anesth 1995; 7: 292-6.
17. Van Hemelrijck J, Smith I, White PF. Use of desflurane for outpatient anesthesia. Anesthesiology 1991; 75: 197-203.

18. Davis PJ, Lerman J, Suresh $S$, et al. A randomized multicenter study of remifentanil compared with alfentanil, isoflurane, or propofol in anesthetized pediatric patients undergoing elective strabismus surgery. Anesth Analg 1997; 84: 982-9.

19. Borgeat A, Popovic V, Meier D, Schwander D. Comparison of propofol and thiopental/halothane for short duration ENT surgical procedures in children. Anesth Analg 1990; 71: 511-5.

20. Hendolin H, Kansanen M, Koski E, Nuutrinen J. Propofol-nitrous oxide versus thiopentone-isoflurane-nitrous oxide anaesthesia for uvulopalatopharyngoplasty in patients with sleep apnea. Acta Anaesthesiol Scand 1994; 38: 694-8.

21. Mukherjee K, Seavell C, Rawlings E, Weiss A. A comparison of total intravenous with balanced anaesthesia for middle ear surgery: effects on postoperative nausea and vomiting, pain and conditions of surgery. Anaesthesia 2003; 58: 176-80.

22. Briggs LP, Dundee JW, Bahar M, Clarke RS. Comparison of the effect of diisopropyl phenol (ICI 35, 868) and thiopentone on response to somatic pain. Br J Anaesth 1982; 54: 307-11.

23. Jevtovic-Todorovic V, Todorovic SM, Mennerick $S$, et al. Nitrous oxide (laughing gas) is an NMDA antagonist, neuroprotectant and neurotoxin. Nat Med 1998; 4: 460-3.

24. Ohashi Y, Guo T, Orii R, Maze M, Fujinaga M. Brain stem opioidergic and GABAergic neurons mediate the antinociceptive effect of nitrous oxide in Fischer rats. Anesthesiology 2003; 99: 947-54.

25. Fassoulaki A, Melemeni A, Paraskeva A, Siafaka I, Sarantopoulos $C$. Postoperative pain and analgesic requirements after anesthesia with sevoflurane, desflurane or propofol. Anesth Analg 2008; 107: 1715-9.

26. Lee WK, Kim MS, Kang SW, Kim S, Lee JR. Type of anaesthesia and patient quality of recovery: a randomized trial comparing propofol-remifentanil total iv anaesthesia with desflurane anaesthesia. Br J Anaesth 2015; 114: 663-8. 